\title{
Axial Selectivity of 1,2-Nucleophilic Additions to 2-(Alkylidene)cyclohexanones: Is It Higher Than That of 2-Cyclohexenones?
}

\author{
Zhengqing You* and Masato Koreeda ${ }^{a}$ \\ *1550 Chew Strect, Allentown, PA 18102 \\ aDepartment of Chemistry, University of Michigan, Ann Arbor, MI 48109
}

\begin{abstract}
Alkylidene)cyclohexanones embedded in steroid systems underwent 1,2-addition of both small and sterically demanding inucleophiles 10 yield exclusively the axial adducts, supporing the suggestion that 2-(alkylidene)cyclohexanones appear to have inurinsically higher axial selectivity than 2-cyclohexenones.
\end{abstract}

Recent research efforts have demonstrated the high stereoselectivity in 1,2-nucleophilic additions to cyclohexenones, and these carbonyl compounds favor the axial addition over the equatorial one in a ratio generally greater than that of their corresponding cyclohexanones. ${ }^{1}$ Rationals for this high selectivity include the concept of continuous orbital overlap between the forming bond and the adjacent carbon-carbon p-orbitals, ${ }^{2}$ the attack trajectory approach, ${ }^{3}$ and the torsional strain analysis. ${ }^{4}$ In our previous publication, we showed an example of remarkable facial selectivity in the 1,2-addition of sterically demanding nucleophiles to a hindered 2-(alkylidene)cyclohexanone (1). ${ }^{5}$ We attributed this bias mainly to the difference between the axial and equatorial attacks in their ability to achieve orbital overlap of the forming bond with the carbon-carbon $\pi$ bond in the transition state, and proposed that this difference is more pronounced for 2-(alkylidene)cyclohexanones (exo-cyclohexenones) than for 2-cyclohexenones (endo-cyclohexenones). These analyses are supported by the most recent theoretical calculations. 6 Thus a difference in stereoelectronic effect between these two types of enone has been revealed and a natural question would be whether they are substantially different in the axial selectivity. One comparison which supports a differentiation is between our exo-enone 1 and endo-enone 2 studieil by Stork and Stryker. ${ }^{7}$ The axial methyl group makes enone 1 more hindered than enone 2, and yet while the latter showed virtually no facial selectivity in 1,2-addition of ethyl lithium, ${ }^{7}$ the former gave a ratio of $5: 1$ in favor of the axial addition of $n$-BuLi. 5
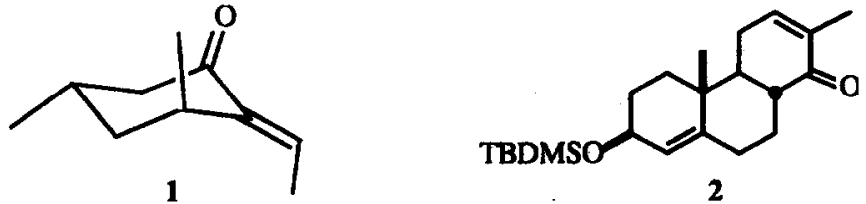

However, documentation of the unusually high stereoselectivity for the exo-cyclohexenones is very limited, and an enrichment in this area can enhance confidence in our understanding of this phenomenon, and provide more reliable guidance for stereoselective synthesis. In addition, although our enone 1 has the 
conformation shown in the low energy state, the mono-cyclic nature of it still leaves some doubt on its rigidity. Therefore it is desirable to have a more rigid exo-cyclohexenone system which would yield no ambiguity in analyzing the stereochemical outcome. Toward these ends we decided to study some hindered exo-

cyclohexenones embedded in steroid systems. Chosen as our starting material was enone 3 which can be easily obtained from cholesterol ${ }^{8}$ whose side chain is abbreviated to $R$ in this paper.

Enone 3 can be regarded as a fusion of an endo-enone and an exo-enone. The methyl group on $\mathrm{C}-10$ produces a steric barrier on the axial side of the carbonyl carbon of the exo-enone portion while the corresponding side of the endo-enone portion is unhindered. Since both exo- and endo-cyclohexenones favor the axial attack in 1,2-nucleophilic additions due to orbital overlap ${ }^{5}$ and torsional strain ${ }^{4}$ factors, it was envisioned that the axial attack at C-3 could become the major mode of 1,2-addition of a bulky nucleophile to enone 3. Thus lithium tris[(3-ethyl-3-pentyl)oxy]aluminohydride was used to reduce enone 3, with enone 4 being the desired product. The reaction, however, yielded a mixture of enones $4(23 \%)$ and $5(54 \%)$. Use of lithium tri-sec-butylborohydride (L-Selectride ${ }^{(2)}$ ) which is probably more sterically demanding, on the other hand, gave enone 4 as virtually the only 1,2-reduction product (36\%) plus 1,4-reduction products. In both reactions, no equatorial 1,2-adduct was detected.

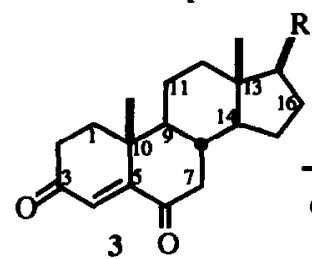

a) $\mathrm{LiAl}\left[\mathrm{OC}(\mathrm{Et})_{3}\right]_{3} \mathrm{H}$ (1.1 equiv), THF, $5-10^{\circ} \mathrm{C}$. or b) L-Selectride ${ }^{(1.1}$ equiv.), THF, $20^{\circ} \mathrm{C}$.

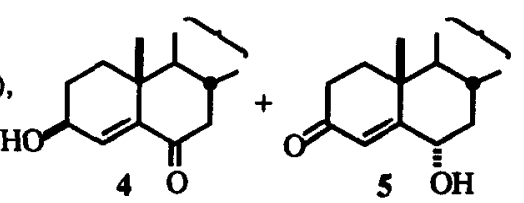

a) $4,23 \% ; 5,54 \%$. b) $4,36 \% ; 5, \sim 1 \%$.

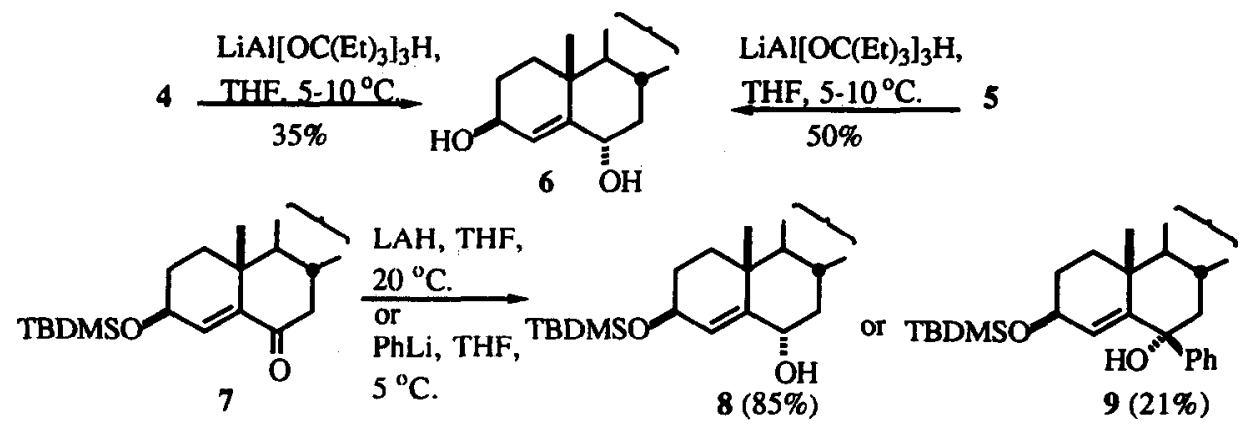

Based on the reduction results of 3 , it was assumed that enones 4 and 5 would give the same diol as their predominant product in 1,2-addition of the bulky aluminum hydride. Indeed, 4 yielded diol 6 as the only 1,2-adduct, while 5 afforded this diol as the major 1,2-adduct with a stereoselectivity of $>20: 1$. When attempts were made to add carbanions to 4 and 5 , the interference of the hydroxyl group prevented any meaningful results. Therefore 4 was treated with $t$-butyldimethylsilyl chloride (imidazol, DMF) to form TBDMSOsubstituted enone 7 (85\%). Due to the abundance of literature examples ${ }^{2}$ for the 1,2 -nucleophilic additions to enones similar to 5, no effort was made to further study it. The B ring (with the carbonyl group) of steroid 7 adopts a chair conformation similar to enone 1. MacroModel ${ }^{9}$ calculations with MM2 force field showed that it has a dihedral angle of approximately $36^{\circ}$ between the carbonyl and olefin planes as compared to $41^{\circ}$ for enone 
1. Not surprisingly, 1,2-addition of both small (LAH) and sterically demanding (PhLi) nucleophiles to enone 7 gave similar results to that of enone $1 .^{5}$ Equatorial alcohols $8(85 \%)$ and $9(21 \%$, plus $70 \%$ of recovered 7$)$ were obtained from LAH ( 2 molar equiv.) reduction and PhLi ( 3 molar equiv.) addition respectively as the only detectable 1,2-adducts.

The structure of alcohol 8 as well as those for enones 4 and 5 were easily assigned based on NMR spectra with proton-proton decoupling studies, showing axial orientation of the protons at C-6 of alcohol 8 $\left(11.6 \mathrm{~Hz},{ }^{3} \mathrm{~J}\right.$-diaxial), $\mathrm{C}-3$ of enone $4(9.5 \mathrm{~Hz}, 3 \mathrm{~J}$-diaxial) and $\mathrm{C}-6$ of enone $5(11.8 \mathrm{~Hz}, 3 \mathrm{~J}$-diaxial). The structure of the phenyl adduct was determined to be 9 based also on NMR data. Thus the methyl on C-10 of 9 was strongly shielded by the phenyl ring with an up-field shift of $0.66 \mathrm{ppm}$ as compared to alcohol 8; the vinyl proton of 9 , on the other hand, was strongly deshielded by approximately $0.62 \mathrm{ppm}$ (down-field shift). Were it a phenyl adduct from the equatorial attack, the methyl at C-10 would not be in the range of phenyl ring shielding, but the vinyl proton could be. Indeed, molecular modeling with the MacroModel program mentioned earlier showed that the axial adduct adopts low energy conformations with the phenyl ring facing the methyl at C-10, while the low energy conformers of the equatorial adduct orient their phenyl ring so that the extension of its plane nearly bisects the B ring through the middle. Included in the references (10-12) are the NMR data ( ${ }^{1} \mathbf{H}$ and ${ }^{13} \mathrm{C}$ ) for the three key compounds enone 7 , alcohol 8 and alcohol 9.<smiles>[R4]O[C@H]1CC[C@@]2(C)C(C1)C(=O)C=C1C3CCC([R])[C@@]3(C)CCC12</smiles><smiles>CC1=C2CCc3ccccc3[C@@]2(C)CCC1=O</smiles><smiles>CC(C)O[C@H]1CC[C@H]2[C@@H]3CCC4=CC(=O)CC[C@]4(C)[C@H]3CC[C@@]12C</smiles>

These results have clearly added evidence for the unusually high axial selectivity of exo-cyclohexenones. Our hindered substrates showed strong axial preference even with sterically demanding nucleophiles, while endo-cyclohexenones do not appear to possess such a propensity. For example, hindered endo-enone 10 was reduced by $\mathrm{NaBH}_{4}$ to just yield the equatorial adduct, ${ }^{2}$ and unhindered enone 11 gave a ratio of only 3:1 in favor of the axial addition of ethyl lithium. ${ }^{7}$ Although enone 5 did exhibit high axial selection in the addition of the bulky aluminum hydride (the methyl on $\mathrm{C}$ - 10 could have a steric effect in favor of the axial addition), its analogs $12 \mathrm{a}$ and $12 \mathrm{~b}$ were only modest in this selectivity when they reacted with $\mathrm{LAH}(3: 1)$ and $\mathrm{NaBH}_{4}(7: 1)$ respectively. ${ }^{2}$ It is interesting to note that treatment of enone 3 with excess LAH ( 3 molar equiv.) affonded alcohols 6 and 13 in a ratio of 3:1, in agreement with the observation that exo-cyclohexenones appear to be more stereoselective than endo-cyclohexenones.<smiles>CC1CC(=O)C2=CC(=O)CC[C@]2(C)C1C</smiles>

3

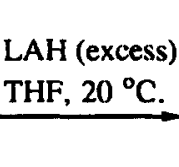

THF, $20^{\circ} \mathrm{C}$.<smiles>CC1CCC2(C)CCC(O)C=C2[C@@H](O)C1</smiles>

6 (55\%)<smiles>CC1[C@@H]2C[C@H](O)C3=C[C@H](O)CC[C@@]3(C)CCC[C@H]12</smiles>

13 (18\%)

In conclusion, we have demonstrated that hindered exo-cyclohexenones $(1,3,4,7)$ undergo 1,2 nucleophilic additions with high axial selectivity even when sterically demanding reagents are used. This lack of sensitivity toward steric hindrance is in contrast to the situation for endo-cyclohexenones. To the best of our 
knowledge, there has not been one example where a hindered endo-cyclohexenone showed a similar selectivity. The ring flexibility for many of the endo-cyclohexenones studied so far could contribute to their apparent sensitivity to the steric effect. And the inherent structural difference betwoen the exo- and endo-enones and the resulting inequality of their axial/equatorial attacks to maintain the orbital overlap between the forming bond and the olefinic p-orbitals may be a major cause.

Acknowledgement We wish to thank the National Institutes of Health for the financial support of this work.

\section{REFERENCES}

1. (a) Trost, B. M.; Florez, J.; and Jebaratnam, D. J. J. Am. Chem. Soc. 1987, 109, 613. (b) Trost, B. M.; Florez, J.; and Haller, K. J. J. Org. Chem. 1988, 53, 2396.

2. Toromanoff, E. In Topics in Stereoselectivity; Allinger, N. L. and Eliel, E. L. Eds.; Interscience: New York; Vol 2, pp 157-198.

3. Baldwin, J. E. J. Chem. Soc. 1976, 738.

4. (a) Wu, Y.-D.; Houk, K. N.; and Trost, B. M. J. Am. Chem. Soc. 1987, 109, 5560. (b) Wu, Y.-D.; Tucker, J. A. and Houk, K. N. J. Am. Chem. Soc. 1991, 113, 5018.

5. Koreeda, M. and You, Z. J. Org. Chem. 1989, 54, 5195.

6. Wu, Y.-D.; Houk, K. N.; Florez, J.; and Trost, B. M. J. Org. Chem. 1991, 56, 3656.

7. Stork, G. and Stryker, J. M. Tetrahedron Lett. 1983, $24,4887$.

8. Fieser, L. F. J. Am. Chem. Soc. 1953, 75, 4386.

9. Still, W. C.; Mohamadi, F.; Richards, N. G. J.; Guida, W. C.; Lipton, M.; Liskamp, R.; Chang, G.; Hendrickson, T.; DeGunst, F. and Hasel, W. MacroModel V3.0, Department of Chemistry, Columbia University, New York, NY 10027.

10. Enone 7. ${ }^{1} \mathrm{H}-\mathrm{NMR}\left(300 \mathrm{MHz}, \mathrm{CDCl}_{3}\right): 6.095\left(\mathrm{H}_{4}, \mathrm{dd}, J=2.0,1.4 \mathrm{~Hz}\right), 4.224\left(\mathrm{H}_{3}\right.$, ddd, $J=10.0$, $6.4,2.0 \mathrm{~Hz}), 2.541\left(\mathrm{H}_{7 \beta}\right.$, br d, $\left.J=15 \mathrm{~Hz}\right), 2.060\left(\mathrm{H}_{1 \beta}\right.$, ddd, $\left.J=12.7,4.0,3.0 \mathrm{~Hz}\right), 0.988\left(\mathrm{Me}_{10}, \mathrm{~s}\right)$, $0.916(\mathrm{Me}, \mathrm{d}, J=6.6 \mathrm{~Hz}), 0.893(t-\mathrm{Bu}, \mathrm{s}), 0.866(\mathrm{Me}, \mathrm{d}, J=6.6 \mathrm{~Hz}), 0.863(\mathrm{Me}, \mathrm{d}, J=6.6 \mathrm{~Hz})$, $0.690\left(\mathrm{Me}_{13}, \mathrm{~s}\right), 0.078(\mathrm{MeSi}, \mathrm{s}), 0.071$ (MeSi, s). ${ }^{13} \mathrm{C}-\mathrm{NMR}\left(75.5 \mathrm{MHz}, \mathrm{CDCl}_{3}\right): 202.62$ (C-6, s), 145.55 (C-5, s), 134.20 (C-4, d), 67.98 (C-3, d), 56.71 (d), 56.00 (d), 51.31 (d), 46.35 (t), 42.57 (s), $39.45(t), 39.38(t), 38.05(\mathrm{~s}), 36.08(t), 35.66(d), 34.92(t), 34.05$ (d), 28.51 (t), $28.02(t), 27.98$ (d), $25.85[\mathrm{C}(\mathrm{Me}) 3, \mathrm{q}], 23.91(\mathrm{t}), 23.77(\mathrm{t}), 22.77(\mathrm{q}), 22.52(\mathrm{q}), 20.76(\mathrm{t}), 19.87(\mathrm{q}), 18.63(\mathrm{q})$, $18.18\left[\mathrm{C}(\mathrm{Me})_{3}, \mathrm{~s}\right], 11.92(\mathrm{q}),-1.131$ (MeSi, q), -1.197 (MeSi, q).

11. Alcohol 8. ${ }^{\mathrm{H}} \mathrm{-NMR}\left(300 \mathrm{MHz}, \mathrm{CDCl}_{3}\right): 5.542\left(\mathrm{H}_{4}, \mathrm{br} \mathrm{d}, J=1.7 \mathrm{~Hz}\right), 4.27-4.19\left(\mathrm{H}_{3}, \mathrm{~m}\right), 4.167\left(\mathrm{H}_{6}\right.$, $\mathrm{dm}, J=11.6 \mathrm{~Hz}), 1.518(\mathrm{OH}, \mathrm{d}, J=5.0 \mathrm{~Hz}), 1.034\left(\mathrm{Me}_{10}, \mathrm{~s}\right), 0.910(t-\mathrm{Bu}, \mathrm{s}), 0.900(\mathrm{Me}, \mathrm{d}, J=6.6$ $\mathrm{Hz}), 0.864(\mathrm{Me}, \mathrm{d}, J=6.6 \mathrm{~Hz}), 0.860(\mathrm{Me}, \mathrm{d}, J=6.6 \mathrm{~Hz}), 0.673\left(\mathrm{Me}_{13}, \mathrm{~s}\right), 0.098(\mathrm{MeSi}, \mathrm{s}), 0.088$ (MeSi, s). ${ }^{13} \mathrm{C}-\mathrm{NMR}\left(75.5 \mathrm{MHz}, \mathrm{CDCl}_{3}\right): 148.05(\mathrm{C}-5, \mathrm{~s}), 120.93(\mathrm{C}-4, \mathrm{~d}), 68.96$ (d), 68.60 (d), 56.25 (d), 55.93 (d), 54.49 (d), 42.56 (s), 42.00 (t), 39.78 (t), 39.52 (t), 37.86 (s), 36.38 (t), 36.16 (t), 35.74 (d), 34.38 (d), 29.41 (t), 28.13 (t), 27.99 (d), 26.03 [C(Me) 3, q], 24.21 (t), 23.84 (t), 22.76 (q), 22.52 (q), $20.96(\mathrm{t}), 19.55$ (q), 18.66 (q), 18.31 [C(Me) 3, s], 11.95 (q), $-1.19(\mathrm{MeSi}, \mathrm{q}),-1.29$ (MeSi, q).

12. Alcohol 9. ${ }^{1} \mathrm{H}-\mathrm{NMR}\left(300 \mathrm{MHz}, \mathrm{CDCl}_{3}\right): 7.528(2 \mathrm{H}$, phenyl, br d, $J=7.8 \mathrm{~Hz}), 7.338(2 \mathrm{H}$, phenyl, br dd, $J=7.8,6.7 \mathrm{~Hz}), 7.258(1 \mathrm{H}$, phenyl, br $\mathrm{t}, J=6.7 \mathrm{~Hz}), 6.160\left(\mathrm{H}_{4}\right.$, br s), $4.343\left(\mathrm{H}_{3}\right.$, ddd, $J=9.8$, $6.1,1.8 \mathrm{~Hz}), 2.724\left(\mathrm{H}_{7 \beta}, \mathrm{dd}, J=13.2,2.9 \mathrm{~Hz}\right), 0.952(t-\mathrm{Bu}, \mathrm{s}), 0.898(\mathrm{Me}, \mathrm{d}, J=6.6 \mathrm{~Hz}), 0.874$ (Me, d, $J=6.6 \mathrm{~Hz}), 0.869(\mathrm{Me}, \mathrm{d}, J=6.6 \mathrm{~Hz}), 0.641\left(\mathrm{Me}_{13}, \mathrm{~s}\right), 0.373\left(\mathrm{Me}_{10}, \mathrm{~s}\right), 0.145(\mathrm{MeSi}, \mathrm{s})$, 0.137 (MeSi, s). ${ }^{13} \mathrm{C}$-NMR (75.5 MHz, $\mathrm{CDCl}_{3}$ ): 147.37 (s), 144.30 (s), 128.56 (d), 127.58 (d), 126.38 (d), 126.17 (d), 74.13 (C-6, s), 69.24 (C-3, d), 56.19 (d), 56.12 (d), 54.99 (d), 43.49 (t), $42.57(\mathrm{~s}), 39.75(\mathrm{t}), 39.59(\mathrm{t}), 38.26(\mathrm{~s}), 37.69(\mathrm{t}), 36.24(\mathrm{t}), 35.83(\mathrm{~d}), 33.48(\mathrm{~d}), 29.11(\mathrm{t}), 28.28(\mathrm{t})$, 28.06 (d), 26.09 (C(Me) $3, q), 24.37$ (t), 23.88 (t), 22.85 (q), 22.60 (q), 21.05 (q), 20.86 (t), 18.70 (q), $18.40\left[\mathrm{C}(\mathrm{Me})_{3}, \mathrm{~s}\right], 12.07(\mathrm{q}),-4.36(\mathrm{MeSi}, \mathrm{q})$. 